\title{
An African perspective on the partiality and impartiality debate: Insights from Kwasi Wiredu's moral philosophy
}

\section{Motsamai Molefe}

To cite this article: Motsamai Molefe (2017) An African perspective on the partiality and impartiality debate: Insights from Kwasi Wiredu's moral philosophy, South African Journal of Philosophy, 36:4, 470-482, DOI: 10.1080/02580136.2017.1342465

To link to this article: https://doi.org/10.1080/02580136.2017.1342465

曲 Published online: 26 Nov 2017.

Submit your article to this journal $\pi$

Q View related articles $\llbracket$

View Crossmark data $₫$ 


\title{
An African perspective on the partiality and impartiality debate: Insights from Kwasi Wiredu's moral philosophy
}

\author{
Motsamai Molefe \\ University of KwaZulu-Natal, Pietermaritzburg, South Africa \\ molefem@ukzn.ac.za
}

\begin{abstract}
In this article, I attempt to bridge the gap between partiality and impartiality in moral philosophy from an oft-neglected African perspective. I draw a solution for this moral-theoretical impasse between partialists and impartialists from Kwasi Wiredu's, one of the most influential African philosophers, distinction between an ethic and ethics. I show how an ethic accommodates partiality and ethics impartiality. Wiredu's insight is that partialism is not concerned with strict moral issues.
\end{abstract}

\section{Introduction}

One of the long standing problems in moral philosophy is whether morality is best construed in terms of partiality or impartiality (Warnock 1971; Singer 1979; Cottingham 1983; 1986; Wiredu 1992; Gyekye 2004; Musschenga 2005; Metz 2010; Molefe 2016a). "Partiality", roughly, refers to the idea that we have prior or even greater duties to our special relationships; and, "impartiality" that we ought to treat all human beings equally. The challenge here is reconciling duties that arise from equalitarian and universal features of morality - the impartiality thesis; and, those arising from our special relationships - the partiality thesis.

In this article, I draw from Kwasi Wiredu's ${ }^{1}$ moral philosophy to proffer a solution to this moral-theoretical impasse between partialism and impartialism. I submit that an under-explored exposition of Wiredu's distinction between what he calls an "ethic" and "ethics" promises to bridge the gap between partiality and impartiality (Wiredu 1992, 193; 2005, 45). My submission is that the element of ethic is congruent with partiality, and that of ethics with impartiality, and that both these facets are a function of human existence that is characterised by the duality of being part of the whole human family and also belonging to some subgroup.

I am aware that some scholars have tried, in the Western tradition, to solve this problem (Wolf 1992; Adams 1993). The general tendency in the Western literature is for scholars to show that the tension between partiality and impartiality is not as great as originally imagined (Baron 1991). Or, some scholars think that moderate kinds of impartiality that urge that we should think of the role of morality in less demanding terms can accommodate the fact that "relationships of friendship and love...rank among the greatest goods of life" (Wolf 1992, 243). Others insist on strict impartiality as being a primary moral consideration and special relationships as secondary (moral) considerations insofar as they are ultimately regulated by morality without making morality qua impartiality dehumanising (Adams 1993). Wiredu's solution is much closer to the last solution. For him, morality, in the strict sense, is essentially defined in terms of impartiality; and, concerns of partiality are not strictly moral ones, but both are crucial since they are a function of a dual facet of human existence. ${ }^{2}$

1 Kwasi Wiredu is truly an elder of African philosophy, boasting more than 40 years as a professional philosopher. I am not suggesting that his philosophical work must be regarded merely because of the quantity of time he spent as a philosopher. There is, however, compelling evidence that legitimates and demands that we should take Wiredu's philosophical work seriously. He is a Professor Emeritus at the University of South Florida; he has held a number of visiting professorships internationally; he has served on a number of distinguished committees and his publication record speaks volumes about the quality of his work. It is for this reason that I decided to explore the ethical work of this seasoned African philosopher, who has been exploring various issues in the African tradition.

2 Below, I will introduce the reader to the distinction Wiredu draws between morality in the strictest sense and morality in a broad sense. 
The following clarifications with regard to this project are crucial. Firstly, this exposition and interpretation of Wiredu's moral philosophy does not already presuppose that it is plausible. ${ }^{3}$ My sole aim is to argue that some under-explored interpretation of it proffers a useful framework for accommodating both partiality and impartiality. Secondly, I engage in this project of bridging the gap between partiality and impartiality to stimulate research in African ethics on the topics of partiality and impartiality, which are largely ignored. ${ }^{4}$ One finds little (in the literature) that concerns itself with the topics of partiality and impartiality in this tradition (Appiah 1998; Gyekye 2004; Bell and Metz 2011; Molefe 2016a; 2016b); and, the little one finds is generally unsatisfactory as it is left merely at a level of moral anthropology or moral intuition (Appiah 1998; Gyekye 2004, 161; Metz 2009, 52). This research is, therefore, one way to speak to this lacuna in the literature on African ethics and it is also an attempt to make a contribution to this debate from an African perspective.

Finally, here, I am offering what I consider to be a promising interpretation of Wiredu's moral philosophy which unifies the two facets of his moral thought to solve one of the long-standing debates between partialists and impartialists from an oft-neglected African perspective. Wiredu's insight here is that we should recognise the difference between "strict" moral issues, which are by nature impartial, from "broad" moral issues, which are partial (Wiredu 1996a, 64; 2005, 49). Impartiality, according to Wiredu, is a function of tracking a universal norm of equalising the well-being of all human beings; and, partiality tracks those customary norms that are a local attempt to make sense of human well-being. The solution adumbrated here is that concerns of partiality are not part of morality in the strict sense without implying that they are not important considerations since both these facets of moral philosophy are a necessary function of human existence.

To unfold Wiredu's moral philosophy in order to bridge the gap between partiality and impartiality, I structure this article as follows. I begin by distinguishing between the notions of ethic and ethics. Secondly, I establish the relation between an ethic and partiality. Here, I argue that communitarianism and personhood, can reasonably be construed to amount to partialism. I proceed, next, to argue that ethics naturally tends to impartiality. I then proceed to bridge the gap between partiality and impartiality by pointing to the dual nature of human existence, which necessarily implicates (1) all human beings in culture-independent ethical questions pertaining to their survival and flourishing, and (2) the existence of human beings in some subgroup/s (family, friends) that require their survival and flourishing at this level as well. To conclude, I will consider some objections, mainly concerns from those that think special relationships like friendship and love are strict moral issues.

\section{Ethic and ethics}

To distinguish these two concepts, an ethic and ethics, I begin with this quotation:

...reflection should help us to grasp the difference between morality, as defined by the Golden Rule, and Communitarianism or individualism as an ethic (Wiredu 2008, 334).

Here, Wiredu draws a crucial distinction that informs this entire article. On the one hand, he talks about morality qua the golden rule; and, on the other, he talks about an ethic qua either communitarianism/individualism. So, at this stage, it is safe to note whatever the content of the golden rule and that of communitarianism, these two are concerned about two distinct sorts of considerations. Wiredu further informs us that morality qua the golden rule refers to morality in the "pure" or "strict sense"; and, ethic qua communitarianism/individualism refers to morality in a "broad" sense (Wiredu 2005, 45, 49; 2008, 334, 336).

Wiredu informs us that morality in the strict sense has the feature of "universal intrinsic obligatoriness": this phrase implies that morality is mind-independent and culture-independent and, thus its rules govern all human relations - "morality in the strict sense is the same everywhere" (Wiredu 1996a, 62, 64; 2005, 46). On the other hand, an ethic refers to the idea that "[e]very society has its own contingent ways of regulating behaviour" (Wiredu 2005, 46; see also 1996b, 30). These

3 Elsewhere, I have questioned the plausibility of Wiredu's moral theory (Molefe 2016b).

4 Some find this strange given that the solution I highlighted above are from Anglo-Saxon literature. The reason for this is that African scholars have not addressed themselves to these issues, at least, so far as I am aware. 
are culture-specific rules for regulating human interactions and they arise in light of circumstances, crises and opportunities in particular localities - these are not the same everywhere (Wiredu 1996a; 2005).

In light of the above elucidation, we can observe that "ethics" refers to moral truths that are necessary for human life as such, without such moral truths human life as a whole would be in jeopardy (Wiredu 1996a). These universal or culture-independent moral truths are captured by the golden rule or what Wiredu refers to as "sympathetic impartiality" (Wiredu 1992, 194, 198; 1996b, $29,41,170) .{ }^{5}$ On the other hand, an "ethic" refers to rules for human conduct that are contingent; more specifically, it refers to customs crucial for the "well ordering of specific human interactions or activities" (Wiredu 2005, 45). Thus, an ethic refers to subgroup-specific rules and/or norms for regulating human life in these groups; and ethics refers to "necessary laws for (all) human behaviour" (ibid.). And, I might add, both are needed for a robust human life. In what follows, I zoom in on the relation between an ethic and the idea of partiality.

\section{Ethic and partiality}

What is the relation between an ethic and partiality? I observe that Wiredu does not explicitly make the link I attempt to make between an ethic and partiality, but I think it is latent in his writings. I submit this link is to be found in his interpretation of an African ethic ${ }^{6}$ to amount to a communal society, which places on an individual a duty to achieve the status of "personhood" (Wiredu 1992; 2008). The very idea of communitarianism is usually understood as one that emphasises a kinship structure that operates on a partialist framework, where one's loved ones, be they immediate family or kin, take priority over others (Appiah 1998; Wiredu 2008, 333). And, secondly, the very concept of personhood is generally interpreted in the literature in African ethics to imply a self-realisation account of ethics, which renders it as amounting to partiality (Molefe 2016b).

I submit that Wiredu's discussion of an ethic always construes it in terms of communitarianism (see Wiredu 1992, 198-200; 2005, 45-51; 2008, 336-340). And he also connects communitarianism with the idea of personhood (ibid.). For example, Wiredu $(2008,336)$ notes:

However, no thought experiment is going to reveal to us the components of the communalist ethic. ${ }^{7}$ It is therefore of a matter of great interest that some of the basic communalistic values of traditional African society can be read off the traditional conception of personhood.

Wiredu informs us that one sure way to understand values characterising an Afro-communitarian ethic can be harvested from the notion of personhood. To illuminate some of the values pertinent in an African communitarian ethic, Wiredu informs us that it concerns itself with issues pertaining to dress, gender and socialisation, friendship, courting and marriage, how to raise children, conventions relating to death, grieving and burial, among others (Wiredu 1992, 193; 2005, 46). It is obvious that these are crucial features of a human life. It is key to note that when he refers to these as "moral", he means morality in a broad sense that invokes customary rules or non-universal norms for regulating behaviour in a subgroup context (Wiredu 1996a).

To describe the rules or norms in question as contingent or as customary is to distinguish them from strict moral ones, but it is not to denude them of their relevance and potency. These contingent norms are crucial because morality in the strictest sense, though necessary, does not settle all questions of human life (Wiredu 1992; 2005; Wolf 1992). For example, solutions and resources for dealing with the loss of a loved one will not be found in ethics. Morality in the strictest sense is just one facet of our life, among many others.

Thus, Wiredu's talk of an African ethic as communitarian, and not individualistic as is typical in the Western context, demonstrates how different societies attempt to address some of the crucial questions pertaining to human life that are beyond the scope of morality in the strict sense (Wiredu

\footnotetext{
Wiredu treats these two as equivalent or interchangeable; or, so I read him.

6 I draw a distinction between an "African ethic" - customary rules salient in Africa - and "African ethics" - African moral philosophy proper.

7 Here, Wiredu uses the idea of communalist and communitarian somewhat interchangeably to refer to how African people typically organised their societies (see Wiredu 2008, 335).
} 
2008, 334). He defines "communitarianism" as a society wherein personal identity is essentially understood to be a function of our relations in a community; and, these relationships, in turn, engender duties and obligations to promote the welfare of the society at large (Wiredu 2008, 333). Whereas individualism operates largely within a framework that generally emphasises privacy, individual liberties and rights, communitarianism emphasises our obligations and duties to others as weightier, without necessarily jettisoning rights (ibid., see also Menkiti 1984, 180).

To sketch how these two cultural systems differ, consider the following case. When there is a funeral at my neighbour, it is polite and considerate of me to go express my condolences. If my neighbour is working on his farm, it is supererogatory for me to go and assist him. When I help the needy, I am doing them a favour rather than fulfilling my moral duty. This kind of thinking characterises individualism. On the other hand, a communitarian logic imposes on me a truck of other-regarding duties. It is my duty to voluntarily assist my neighbour on his farm and he also has a similar duty. This is usually referred as "mutual aid" (Wiredu 1992, 201). Helping the poor is my duty and falls naturally within the scope of my duties (Metz 2007). When someone passes away in my community, it is my responsibility and that of a community to be with them through the entire ordeal and to contribute towards some of the cost of the funeral. The cost is not only monetary, but social. We may have to house some of their relatives in our own homes and provide food for them. In an individualistic culture, to engage in these activities involves doing more than "morality" requires, and in an African tradition to do less is to be insensitive and self-absorbed (Gyekye 2004; Metz 2007). But, remember here we are dealing with morality in a broad sense. ${ }^{8}$

That communitarianism is at the heart of how traditional Africans organised their societies cannot be questioned (Mbiti 1969, 108-109; Gyekye 1992, 101-102; Mbigi 2005, 75). Individuals understand themselves more as bearers of duties to their families, tribes and communities (Wiredu 2008, 333). Failure to master these contingent rules entailing our duties to others has serious implications for one's reputation or social standing. The concept used to capture this idea of social standing associated with how one succeeds or fails to discharge social obligations in a communitarian context is that of personhood. This notion is at the heart of the Afro-communitarian ethic (Menkiti 1984; 2004; Dzobo 1992; Gyekye 1992; 1997; Wiredu 1992; 2004; 2008; 2009; Behrens 2013; Molefe 2016a). It has to do essentially with the respect an agent earns relative to how she discharges social obligations generated by norms prized in a communitarian setting (Menkiti 1984). This notion of personhood refers to a kind of respect that is performance-based (Darwall 1977). I submit that this Afro-communitarian notion of personhood entails the notion of partiality, or so I will argue. ${ }^{9}$ Below, I elaborate on this notion of personhood and partiality.

Wiredu distinguishes between an ontological and a normative ${ }^{10}$ notion of personhood (Wiredu 1992; 2009). With regard to this distinction, Wiredu $(1992,199)$ observes that

[n]ot only is there what might perhaps be called an ontological basis for this identity in terms of the constituents of personhood, but there is also a distinct normative layer of a profound social significance in that concept.

The ontological notion is concerned particularly with specifying descriptive properties that constitute human nature, whether they are physical or non-physical (Wiredu 2009, 13-14). ${ }^{11}$ Wiredu informs us, however, that normative considerations are "more dominant" in an African tradition (Wiredu 2009, 13). Though everyone is human, not everyone ends up attaining this status of personhood (Menkiti 1984). This moral identity of being a person is associated with moral dispositions or habits one develops by discharging her other-regarding obligations to promote the welfare of others in society (Tutu 1999; Behrens 2013). When we refer to one as a person, we are approving of her moral standing and moral performance (Wiredu 2009). This kind of social approval shows that in Afro-communitarian setting it is not enough merely to be "human in the biological sense"; one is

8 What is a considered a "good" person will vary from society to society depending on the customary norms considered important.

9 It is interesting to note that Wiredu limits the notion of personhood within a communitarian setting, and does not treat it as a universal moral concept.

10 It is crucial to note that the norms informing the normative conception of a person are customary and culture specific.

11 For an informative introductions to the debate on ontological personhood in an African tradition, see Kaphagawani (2004). 
expected "to become a full person, a real self, or a genuine human being, i.e. to exhibit virtue in a way that not everyone ends up doing" (Metz 2009, 83; original emphasis). Achieving moral virtues associated with a communitarian ethos qualifies one as a person, and failure to discharge these communal duties reduces one to the status of a non-person. Wiredu $(1992,200)$ informs us that "[h]abitual default in duties and responsibilities could lead to diminution in one's status as a person in the eyes of the community". And he further tells us that African people make it their mission in life not to lose their social standing in the community (ibid.). Wiredu continues to expose social implications of this notion of personhood in the following manner:

What, then, in its social bearings, is the Akan ideal of personhood? It is the conception of an individual who through mature reflection and steady motivation is able to carve out a reasonably ample livelihood for self, family, and a potentially wide group of kin dependents, besides making substantial contributions to the well-being of society at large. The communalistic orientation of the society in question means that an individual's image will depend rather crucially upon the extent to which his or her actions benefit others than $\mathrm{him} /$ herself, not, of course, by accident or coincidence but by design. The implied counsel, though, is not one of unrelieved self-denial, for the Akans are well aware that charity further afield must start at home (Wiredu 1992, 200).

It is crucial to note that in this passage Wiredu is articulating implications flowing from the idea of personhood. In his analysis of these "social bearings" of this notion, he begins by noting how an individual has to sort out her own issues of life, first by creating an ample livelihood for herself. One has to develop a set of skills that will enable her to function in a communitarian context. It is also crucial to note that Wiredu moves from a self, to family, to a "potentially wide group of kin dependents", and finally to the society at large. It is reasonable to read Wiredu as suggesting that the strength of our obligations decreases as we move out of the circumference (Wiredu 2008; Bell and Metz 2011). Our first and prior duty is to our loved ones, those immediately close to us, and then we can move to kin dependents and finally to society at large. This interpretation of Wiredu begins to suggest the idea of partiality. I am suggesting that we read partiality on the order as outlined by Wiredu above, informed by his assertion that the rule to guide us in discharging our duties is that "charity further afield must start at home". ${ }^{12}$ This maxim rubber-stamps the partialist reading of the order of priority and/or weightier duties I just suggested in the previous sentences, i.e. before we go further afield in terms of fulfilling our obligations to society at large, we must start with those close to us. It is this kind of prioritisation of some subset of people that defines the very idea of partiality (Jollimore 2011). This partiality is naturally at home in societies that are built on kinship structures (Appiah 1998; Wiredu 2008). ${ }^{13}$

Above, we see that the duties that communitarianism imposes on us are framed within a partialist model, where we have a duty to prioritise our special relationships before we go further afield. In other words, I have weightier duties to my loved ones, but these do not exhaust the scope of my moral responsibilities, which extend to the society at large. Thus, though one can - within a communitarian framework - talk about those in the inner and outer circles, the boundaries separating the two are permeable (Ramose 2003, 328). ${ }^{14}$ Hence, Wiredu can talk about one having a duty to start with close relations as if to suggest that one's loved ones ought to take priority, but this does not exhaust the whole scope of morality.

Thus far we have noted how the notion of an ethic implies a communitarian social arrangement that emphasises certain obligations and duties emanating from broad morality. And, we have noted that social duties are critical in one gaining some social standing in society, which is usually captured by the notion of personhood. And, we have also noted that one implication of this idea of

12 I advise the reader to note the obliging nature of the auxiliary verb used in this Akan "rule" - "charity further afield must start at home".

13 Appiah (1998) interestingly observes that kinship structures informing communitarianism are partialist. He notes that "[t]his form of moral thought permits someone, the agent, to treat someone else, the patient, in a certain manner because the two are related...I might give shelter to someone 'because she is my kinswoman'". Thus, if I have two people seeking shelter, one my kinswoman and another a stranger, and I can only help one, it appears that my kinswoman will win the day.

14 Bell and Metz $(2011,89)$, in a discussion of partiality in African ethics, offers an interesting reason for why we should strive to reach to the community at large. 
personhood is the idea of partiality to those close to us, but which does not limit the scope of our other-regarding duties. It simply puts a hierarchy or priorities among them.

I wish now to elaborate more on this idea of personhood to demonstrate that it is essentially a partialist term. I do so by drawing a distinction between other-centred and agent-centred partiality (see Cottingham 1983; 1986). ${ }^{15}$ Above, I suggested that the idea of personhood as adumbrated by Wiredu accommodates the other-centred partiality as it prioritises our loved ones (see also Ramose 2003; Bell and Metz 2011). What, however, has not been identified in the literature is that this notion appears to correspond to something like the projects view in the literature on partiality, which captures agent-centred partiality (Cottingham 1986; Lord 2016). One of the grounds for arguing for partiality in the Western moral tradition is by invoking the idea of projects, first employed by Bernard Williams (1981) in his criticism of Utilitarianism.

Partiality, on the projects view, is grounded on facts about me as an agent. I have goals, relationships and activities and I ought to accord priority to these projects because they are mine, they identify me and they add meaning to my life (Cottingham 1986; Lord 2016). Without these projects, my life would be meaningless and a robust sense of a self will most probably be threatened (Keller 2013; Lord 2016). Why do I buy philosophy books, attend philosophy conferences, write philosophical articles? It is because philosophy is one of my projects insofar I am committed to it to a point of thinking of myself as a philosopher. So the projects view refers to these commitments that I am involved in and that are defining features of $m y$ life. The projects view is tantamount to an agent-centred partiality (Cottingham 1991).

I think a close reading of the literature on the idea of personhood in an African tradition can best be read in terms of the projects view. The idea of personhood identifies my chief goal, which is to attain a particular social standing that is decisive for me in a communitarian ethos (Menkiti 1984; Shutte 2001). If "my life mission" within a communitarian ethic is achieving this status, as Wiredu suggests, it is not farfetched to treat this as my chief project (Wiredu 1992, 200). This project of attaining the status of personhood obviously has other elements like taking care of my family, friends, kin and society (Wiredu 1992; 2008). Ultimately, the rationale for doing so is that it is good for $m e$ as I will be the one gaining this status of personhood. ${ }^{16}$ Thus, following the literature on personhood, we are urged not to read this notion in terms of egoism, but we should read this more within a self-realisation framework (Metz 2007, 331; Shutte 2001, 14). Reading personhood in terms of a self-realisation framework has two elements.

The first element is the question of the nature of personhood itself; and the second element has to do with the means required to achieve this status (Metz 2013; Tshivhase 2013). With regard to the nature of personhood, we have noted that it is a normative status achieved by some relative to their discharge of certain social duties, where one is considered to be leading a genuine human life. With regard to the means necessary for achieving such a status, African scholars also converge on the idea that one achieves it by fulfilling one's other-regarding duties and obligations (Magesa 1997; Ramose 1999; Bujo 2001). For example, Metz $(2009,83)$ states that

...the state of being a (person) is entirely constituted by relating to others in a certain manner...so Africans would characterize an individual who does not relate positively to others as lacking ubuntu, lacking humanness.

It is crucial to note that Metz states that this status of personhood is entirely constituted by positively relating to others. This "positive" relation with others refers to our other-regarding duties (Tutu $1999,35)$. In other words, I can only achieve my goal of being a person by promoting the good of others. And carrying out these responsibilities and duties, in turn, constitutes my moral identity as a person. Thus the idea of personhood calls to mind an other-regarding ethic, but this other-regarding ethic ultimately leads to me achieving the status of personhood. The partiality at play here is manifested by reasons that inform a self-realisation account that I have to realise my true nature (Metz 2007; van Niekerk 2007; Lutz 2009). ${ }^{17}$

15 I adopt this distinction from John Cottingham, who distinguishes between our partiality to our loved ones and agent-related partiality.

16 This is by no means the only rationale (see van Niekerk 2007; Lutz 2009).

17 Another way to make sense of the partiality of personhood is in terms of agent-relative reasons. When one asks me, "why do you help 
Here, we have two sorts of partiality entailed by the Afro-communitarian notion of personhood (Molefe forthcoming). Generally, an agent in Afro-communitarian society is expected to prioritise those close to her as a matter of principle. This insight was hinted at by Wiredu's assertion that charity must begin at home. I referred to this as an other-centred partiality. The second type of partiality, I argued, is entailed by the self-realisation orientation of the notion of personhood, which implies an agent-centred partiality that one achieves by fulfilling one's duties to others.

In this section, I showed how the idea of an ethic is associated with a communitarian outlook, which is best captured by analysing the notion of personhood. I showed how this idea of personhood is associated with two forms of partiality. The above section makes mention of morality and moral ideas. It must be borne in mind, however, that here our analysis is with regard to morality in the broad sense insofar as it is concerned about rules regulating life in some subgroup/s. I proceed now to the idea of ethics and impartiality, which is concerned about morality in the strict sense.

\section{Ethics and impartiality}

Talk of ethics in the strictest sense is helpful largely to distinguish it from the idea of an ethic, but this notion itself is ambiguous. The term "ethics" could mean one of three things (Korsgaard 1983). Firstly, by "ethics" one can mean a theory of right action, which specifies a ground norm (like utility or dignity) invoked to distinguish what all right and wrong actions have in common (see, for example, Metz 2007, 321). Secondly, by "ethics" one can also be answering the question of "what makes a life function best?", where one identifies a moral property that makes a difference in whether one's life functions best or not (Parfit 2002, 134-140). Lastly, one could mean a theory of perfection, that is “what is a good person?" (Menkiti 2004, 324-326). It is safe to interpret Wiredu's talk of ethics to be concerned about the first notion of ethics, a principle of right action.

I observe that Wiredu's moral theory is best construed in terms of welfarism. I understand "welfarism" to be the claim that well-being "is the only value which an ethical theory needs to take seriously, ultimately and for its own sake" (Sumner 1992, 3). ${ }^{18}$ This reading of Wiredu is sustained by some of his remarks. For starters, Wiredu avers that "by our lights, human well-being is an irreducible presupposition of all morality...every moral endeavour is a certain kind of quest after human well-being" (Wiredu 1996a, 64). And he continues to observe that "[e]very Akan maxim about the specifically moral views that I know...postulates the harmonization of interests as the means, and the securing of human well-being as an end, of all moral endeavour" (Wiredu 1996a, 65; emphasis added).

From these two quotations, it is unquestionable that Wiredu posits well-being as the basic norm that grounds his moral theory. This interpretation is supported by his reference to well-being as an irreducible presupposition of all morality. To refer to welfare as "irreducible" is to imply that it is a basic moral truth, and that all other (moral) truths reduce to it. Secondly, Wiredu's language of capturing well-being as an end and harmonisation of interests as a means also captures well-being as the final good, the proper goal of all moral actions. In other words, right and wrong actions are a function of securing human well-being, or actions are right or wrong relative to whether they ultimately achieve or frustrate human well-being. Wiredu believes that the golden rule or the principle of sympathetic impartiality does conduce to well-being of all human beings.

The golden rule and "sympathetic impartiality" are equivalent expressions of ethics (Wiredu 1992, 194, 198; 1996a, 29, 41, 170). Wiredu appears indifferent with regard to whether one addresses the idea of the golden rule positively and/or negatively. This principle functions to harmonise or adjust human interests to the effect of securing human well-being. Why do human interests need to be adjusted or harmonised? The answer to this question is found in the art motif of a crocodile with two heads and one stomach (Wiredu 2009, 10). A message that is communicated by the two heads is that "although human beings have a core of common interests, they also have conflicting interests that precipitate real struggles...the aim of morality...is to harmonize those warring interests through

others in the community?", the reasons I will invoke will essentially have as part of the answer some reference to me - it is good for me, though that answer need not be exhaustive.

18 In this article, I use the ideas of welfare and well-being interchangeably. 
systematic adjustment and adapting" to achieve the common good of securing the well-being of all (1992, 197).

We should remember that Wiredu informed us that harmonisation of interests is the means, and the goal of morality is securing human well-being. The "harmonisation of human interests" is operationalised by appeal to the golden rule, which is ultimately meant to lead to well-being. Here we may ask: how does Wiredu make sense of the golden rule?

Wiredu gives several articulations of the golden rule. In some instances, he represents it positively:

Let your conduct at all times manifest a due concern for the interests of others...a person may be said to manifest a due concern for the interests of others if in contemplating the impact of her actions on their interests, she puts herself imaginatively in their position (Wiredu 1996a, 31).

And, in some instances, negatively: "Do not do unto others what you would not that they do to you" (Wiredu 1992, 198; see also 1996b, 41). Remember that Wiredu equates the golden rule to what he refers to as sympathetic impartiality (Wiredu 1996a, 170). Wiredu also informs us that the principle of sympathetic impartiality requires us to "be willing to put oneself, as the saying goes, in the shoes of others when contemplating an action" (Wiredu 1996b, 237). In another place he states that "[p] ure morality - that is, those requiring of the individual an impartial regard for the interests of others motivated by a certain minimum of altruism - are the most indispensable" $(1999,33)$. He refers to this principle as a test of what might be permissible or impermissible actions. To exemplify how this moral test functions, he evaluates a custom among the Akan people that required servants to be killed so as to accompany and continue to serve their departed king in the afterlife. Wiredu notes:

When it is subjected to this test, it is, of course, found wanting. Why so? Because the custom would seem to run counter to the principle of sympathetic impartiality: Would the king himself welcome an identical treatment in an exchange of stations? Most likely not (1996b, 240-241).

This moral test requires an agent to impartially imagine herself in another's position and ascertain whether she would welcome the action or outcome in question. With regard to the king, he should put himself in the shoes of his servant and consider whether he would be willing to be put to death so as to accompany and serve his king in the afterlife. Wiredu informs us that the king in servant's shoes would probably not accept such a position.

It is crucial to note that this moral theory has two aspects. On the one hand, morality is a function of some moral psychology expressed through the virtues of sympathy/empathy, and on the other, there is the element of impartiality. With regard to sympathy (empathy), Wiredu informs us that it is "the root of all moral virtue" (Wiredu 1996a, 71). In other words, no action can claim the property of being moral (right) if it is not characterised by this feature of manifesting due concern for the welfare of others. The second facet is concerned largely about the scope of manifesting sympathy. Is this sympathy reserved for a subset of people or is to be equally manifested to all people? Wiredu's principle prescribes that the virtue of sympathy must be manifested equally to every human being, hence he calls his theory sympathetic impartiality. In other words, we need to care equally about the welfare of each and every human being. Or, that our sympathy ought not to discriminate among human beings.

So, what emerges poignantly is the impartiality of this principle of right action. To best understand the force of impartiality in this theory, remember the case of the king and his servant. When we enter into the moral domain, Wiredu submits that the fact that one is a king or a servant are irrelevant non-moral considerations. We are aware that a king-servant relation is a special one that engenders partialist considerations insofar as one treats a king in a way she does not usually treat any other human person. But, when we assume a strict moral stance informed by sympathetic impartiality, these titles of being a king and servant fall to the side; what matters is equal consideration of human welfare. What is good for the king's welfare is equally good for the servant's.

On this principle, I can neither show preference to myself, family or friends. When it comes to strict morality, the welfare of all counts and it counts equally. The fact that you are my mother, uncle, child, interesting as it might be, does not factor in the strictest sense of morality. Morality 
defined here shows an orientation to the good of all as represented by the stomach of the two-headed crocodile.

Above, I discussed Wiredu's sympathetic impartiality. I showed how this principle of right action, by its very nature and name, is impartial. It calls upon an agent to equally regard the welfare of all human beings without making any distinctions. Morality in the strictest sense, by its very nature, has no place for special relationships. What we have so far is that the idea of an ethic entails partiality; and that of ethics is overtly impartialist. What remains unclear, however, is how these two features of Wiredu's moral philosophy, the ethic of communitarianism, which is characterised by partialism, and sympathetic impartiality's impartialism can co-exist in this moral framework.

\section{Bridging partiality and impartiality}

How do these two disparate features of Wiredu's moral philosophy, Afro-communitarianism qua ethic, and sympathetic impartiality qua ethics hold together? Asking this question is tantamount to requiring us to fix the gulf between partiality and impartiality, at least in light of Wiredu's moral philosophy, which does have implications for the conundrum of partiality and impartiality in broader moral philosophy. Wiredu's solution involves appreciating the fact that these two do not diverge or are not necessarily opposed to each other. In fact, the idea is that considerations of impartiality are foundational and those of partiality are supplementary. This means that morality in the strict sense responds to facts of human beings as part of the whole human family, and morality in its broad sense responds to facts of a human being as a part of some subgroup $(s)$. These two facets of human existence are crucial for a robust or even a complete human life.

Considerations of being a part of the whole human race are foundational insofar as they serve as the basis for securing or guaranteeing the continuance of the human project. They serve as those moral rules that apply to all human cultures and upon which all human cultures depend. These rules depart from the fact of the equality of the interests of all human beings. It is for this reason that these rules are best accounted for on the basis of impartiality. It is for this very reason that Wiredu dubs his moral theory, as previously mentioned, sympathetic impartiality, signalling that we must consider the well-being of all human beings equally, hence the insistence on impartiality as a regulative facet of this principle of right action.

But, Wiredu equally recognises that a human being does not only exist as a member of the whole human community, but also as a member of some subgroup(s) like family, friends and so on. That is, a human being is born to some specific mother and father, in a particular family, in a particular culture and so on. Just like human life in its universal dimension has ethics regulating it, even so in its subgroup dimension it requires regulations that are responsive to the particularity of this facet of human existence. Some may here wonder why ethics is not invoked to regulate human life in its subgroup dimension.

It is important to recognise Wiredu's insistence on this distinction of ethics and ethic because he appreciates the dual form that attends to human existence: a member of the human group, and a member of some subgroup. Wiredu clearly appreciates these two facets of humanity as inevitable and inescapable, i.e. a human life will be unfortunate without either of the two. A human life is equally unfortunate without universal moral rules like human rights as it is without a family or friendship. Sympathetic impartiality essentially seeks to equally consider the well-being of every human being since every human being is equal in her interests to every other. And, the value of prioritising the family or friends functions within the frame of partialism, wherein one puts priority over her family because of facts of belonging to this subgroup. But Wiredu is aware of the limitations of ethics in the strictest sense.

For example, Wiredu $(2008,334)$ informs us that "[m]orality in this strict sense is absolutely essential for the continuation of human society. But it is not sufficient for the regulation of all aspects of human interaction". Or, in the words of Kwame Gyekye (1997, 47), "life is not all morality" in the strict sense. In other words, morality in the strict is inadequate (though necessary) to address all human issues pertaining to human existence. It is this fact of the inadequacy of ethics as a universal and foundational facet of human existence that necessitates an ethic. This inadequacy 
finds answers in Afro-communitarianism, of which Wiredu informs us that it "embodies specific answers to questions of this sort" (Wiredu 2008, 334).

These particular answers that are born out of our existence in subgroups as embodied in Afro-communitarianism are supplementary in the sense that they speak to a sufficient/complete moral philosophy that adequately addresses the totality of humanity in its dual existence. So, ethics regulates human interactions that are absolutely necessary for the continuation of the human project as a whole, where impartiality is a defining feature, and an ethic regulates those that have to do with questions of "custom", born out of our existence in some subgroup, providing answers to questions concerning manners of eating, dress, raising of children, courting, friendship, marriage and so on (Wiredu 1992, 193). But, what does it mean precisely to say ethics is foundational and an ethic is supplementary? What exactly is the relationship between these two?

Before elaborating on these questions, it is crucial to emphasise that these are two necessary features of human existence. In other words, in this thinking, impartiality and partiality arise precisely because of the nature and function of what it means to be human: a member of a whole and a subgroup simultaneously. The bridge that Wiredu is proposing amounts to merely appreciating the duality of human existence. In her existence, if it is to be robust and true to what it means to be human, it ought to speak to her existence within a whole and within a subgroup. Thus, impartiality and partiality are crucial features of human existence itself.

Now I can shed some light on the relationship between the two by considering instances where they may appear to diverge. Impartiality is foundational and partiality is supplementary in the sense to emerge in the discussion below. So, what happens when impartiality and partiality conflict? Well, a simple answer to this situation is that, all things being equal, ethics and an ethic need not do so since the latter supplements the former, knitted together to ensure human well-being. We have little reason to expect many conflicts in this regard. Both ethics and an ethic ultimately are concerned about rules that attempt to adjust or harmonise human interests underpinned by the pursuit of human welfare (Wiredu 2008, 333-334). The difference is that other rules so conceived are based on particular considerations and may be ill-conceived, but they may be adjusted or even jettisoned in light of the golden rule, which invokes rules meant to secure the equality and well-being of all human beings.

For example, remember the custom among the Akan people that requires that servants be killed to accompany their king to the afterlife. The relationship of a king and servants is a special one, characterised by partiality. The king enjoys a higher status than servants and the king is treated in ways that other people are usually not treated. The underlying rationale of this ethic is not faulty given that servants are killed not to harm them, but to send them off to facilitate the welfare of their king. So the problem, in the first approximation, is not the rationale of the ethic per se, but the metaphysics that believes in the afterlife (Wiredu 1996b). So this culture, correctly construed, does not appear to question the universal value of human well-being, it interprets it in light of a faulty metaphysics of an afterlife where servants will continue serving their king as they were doing before his demise.

Though most people will be willing to abandon the facet of killing servants to accompany their kings to the afterlife, very few would want to jettison the custom of kings and their servants per se. The aspect of killing is wrong ultimately because it fails to appreciate the equality of human beings and their equal standing in the human community, but as soon as we solve that facet of killing servants, there is no need to further remove those facets of an ethic that supplement the strict morality that emphasises certain special relationships within certain subgroups like having kings and servants, so long as these do not undermine the universal facets of morality.

For another useful example typical in discussions of partiality, consider the case of two drowning children, and you can only save one. One of these children happens to be yours. How does one respond to this case given Wiredu's moral philosophy? Since there is no question about the children's equality, then how does one broker this situation? Given that both my child and that of a stranger are equal, and if we only had considerations of them being members of the human family, we would have no non-arbitrary basis to choose one over the other. But the extra fact that the other is 
a member of $m y$ subgroup occasions supplementary considerations that would justify my selecting my child over that of a stranger's.

This case, properly understood, does not undermine the equality of the child that is not saved. When we have exhausted those considerations (of their equality), we still have issues arising from an ethic. It is these other considerations that attend a human life that explain why I save my child rather than a stranger's. So, considerations of partiality depend rather than supersede impartiality.

A major concern against this kind of solution might be that it fails to appreciate the high value usually attached to the institutions of friendship and love, by merely relegating them to an ethic status. The objection here is that things like love and friendship are universal features of human life, and, as such, they are a part of ethics. For example, Thad Metz $(2007 ; 2009)$ defends a relationshipbased view of partiality in African ethics, where friendship is understood to be intrinsically valuable. ${ }^{19}$ Here I am prepared to bite the bullet and insist that friendship and love relationships, though universal, in some sense, are not intrinsically obligatory like rules of ethics. ${ }^{20}$ There is a sense in which I cannot imagine a human life without a value of honesty being intrinsic to human social existence, but I can somewhat imagine a human life without friendship or even a romantic relationship. In other words, these relationships lack that property of being intrinsically obligatory in the way the value of honesty is.

But, the force of Wiredu's argument is not the reduction of the institutions of friendship and love, it is rather putting them in a more plausible light. In other words, though the well-being of all counts equally - ethics - friendship and love, give us supplementary reasons to favour our loved ones over strangers. In other words, partiality is not opposed to human equality, in fact it departs and depends on it. It is when we have satisfied its considerations that we can equally proceed to consider other important facts that attend to human life that may occasion partiality. Though the lady next door is equal to my wife as a human being, I may not treat them equally because supplementary considerations will tilt the scale to my subgroup, my wife. As such, this account explains partiality in a way that does not deny impartiality.

If my exposition and interpretation of Wiredu is true, then we see how the impasse between partiality and impartiality can be resolved from an under-explored African moral perspective. Impartiality deals with proper moral issues that have to do with survival of human beings as such, and partiality deals with particular issues of human existence that are not strictly moral. The domain of universality is characterised by impartiality, and the terrain of particularity is characterised by partiality. Both partiality and impartiality are two characteristic features of human existence; one concerned about the well-being of all humanity, and one concerned about facilitating well-being at a level of subgroups.

\section{Conclusion}

In this article, I visited Wiredu's moral philosophy to ascertain possible contributions he might make on the partiality-impartiality impasse. In my analysis, I observed that the Afro-communitarianism (ethic) that emphasises the notion of personhood accommodates an agent-centred and other-centred partiality. I also showed how sympathetic impartiality as a principle of right action is essentially characterised by impartiality. We bridged the gulf between the two by arguing that they are both essential features of human existence. A human being as a member of the human family is regulated by rules of equality, and as a member of a subgroup is regulated by rules that occasion partiality. For future research, it might be important to compare this solution that grounds partiality and impartiality as a function of the dual nature of human existence with others in the literature. For this research, it suffices to highlight insights from an oft-neglected African perspective.

\section{Acknowledgement}

I am truly grateful to the comments offered by the three reviewers to make this paper stronger than it would have been without their insightful comments.

19 Elsewhere, I demonstrate the inadequacies of this moral theory. Specifically, I argue that it offers unattractive reasons for partiality; and, it also fails to accommodate agent-centred partiality (Molefe 2017).

20 It is "universal" in a sense that every person is a member of some subgroup. 


\section{References}

Adams, D. 1993. "Love and Impartiality." American Philosophical Quarterly 30: 223-234.

Appiah, A. 1998. "Ethical systems, African." In: Routledge Encyclopedia of Philosophy, edited by E. Craig. http://0-www.rep.routledge.com.ujlink.uj.ac.za:80/article/Z008SECT5.

Baron, M. 1991. "Impartiatlity and Friendship." Ethics 101(4): 836-857. doi:10.1086/293346.

Behrens, K. 2013. “Two Normative Conceptions of 'Personhood'.” Quest 25: 103-119.

Bell, D. A. and T. Metz. 2011. "Confucianism and Ubuntu: Reflections on a dialogue between Chinese and African traditions." Journal of Chinese Philosophy 38: 78-95. doi:10.1111/j.1540-6253.2012.01690.x.

Bujo, B. 2001. Foundations of an African Ethic: Beyond the Universal Claims of Western Morality. New York: The Crossroad Publishing Company.

Cottingham, J. 1983. "Ethics and Impartiality." Philosophical Studies 43(1): 83-99. doi:10.1007/ BF01112524.

Cottingham, J. 1986. "Partiality, Favouritism and Morality." Philosophical Quarterly 36(144): 357-373. doi:10.2307/2220190.

Cottingham, J. 1991. “The Ethics of Self-Concern.” Ethics 101(4): 798-817. doi:10.1086/293344.

Darwall, S. 1977. “Two Kinds of Respect.” Ethics 88(1): 36-49. doi:10.1086/292054.

Dzobo, K. 1992. "Values in a Changing Society: Man, Ancestors and God." In: Person and Community: Ghanaian Philosophical Studies, 1, edited by K. Gyekye and K. Wiredu, 223-242. Washington, DC: Council for Research in Values and Philosophy.

Gyekye, K. 1992. "Person and Community in African Thought." In: Person and Community: Ghanaian Philosophical Studies, 1, edited by K. Gyekye and K. Wiredu, 101-122. Washington, DC: Council for Research in Values and Philosophy.

Gyekye, K. 1997. Tradition and Modernity: Philosophical Reflections on the African Experience. New York: Oxford University Press.

Gyekye, K. 2004. Beyond Cultures: Perceiving a Common Humanity, Ghanaian Philosophical Studies. Accra: The Ghana Academy of Arts and Sciences.

Jollimore, T. 2011. "Impartiality." In: The Stanford Encyclopedia of Philosophy, edited by E. N. Zalta. http://plato.stanford.edu/archives/sum2011/entries/impartiality/.

Kaphagawani, D. 2004. "African Conceptions of a Person: A Critical Survey." In: A Companion to African Philosophy, edited by K. Wiredu, 332-442. Oxford: Blackwell Publishing.

Keller, S. 2013. Partiality. Princeton: Princeton University Press. doi:10.1515/9781400846382.

Korsgaard, C. 1983. "Two Distinctions in Goodness.” Philosophical Review 92(2): 169-195. doi: $10.2307 / 2184924$.

Lord, E. 2016. "Justifying Partiality." Ethical Theory and Moral Practice: An International Forum 19: 569-590.

Lutz, D. 2009. "African Ubuntu Philosophy and Global Management." Journal of Business Ethics 84(S3): 313-328. doi:10.1007/s10551-009-0204-z.

Magesa, L. 1997. African Religion: The Moral Traditions of Abundant Life. New York: Orbis Books.

Mbigi, L. 2005. The Spirit of African Leadership. Randburg: Knowers.

Mbiti, J. 1969. African Religions and Philosophy. London: Heinemann.

Menkiti, I. 1984. "Person and Community in African Traditional Thought." In: African Philosophy: An Introduction, edited by R. A. Wright, 171-181. Lanham: University Press of America.

Menkiti, I. 2004. "On the Normative Conception of a Person." In: A Companion to African Philosophy, edited by K. Wiredu, 324-331. Oxford: Blackwell Publishing.

Metz, T. 2007. "Toward an African Moral Theory." Journal of Political Philosophy 15(3): 321-341. doi:10.1111/j.1467-9760.2007.00280.x.

Metz, T. 2009. "African and Western Moral Theories in Bioethical Context." Developing World Bioethics 10(1): 49-58. doi:10.1111/j.1471-8847.2009.00273.x. 
Metz, T. 2010. "Human Dignity, Capital Punishment and an African Moral Theory: Toward a New Philosophy of Human Rights." Journal of Human Rights 9(1): 81-99. doi:10.1080/14754830903530300.

Metz, T. 2013. "Two Conceptions of African Ethics in the Work of D A. Masolo." Quest 25: 7-15.

Molefe, M. 2016a. "African Ethics and Partiality." Phronimon 17(2): 104-122. doi:10.17159/2413-3086/2016/142.

Molefe, M. 2016b. "A Critique of Kwasi Wiredu's Humanism and Impartiality." Acta Academica 48(1): 89-108. doi:10.18820/24150479/aa48i1.5.

Molefe, M. 2017. "Relational Ethics and Partiality: A Critique of Thad Metz's 'Towards an African Moral Theory"'. Theoria 64: 43-61.

Molefe, M. forthcoming. "Personhood and Partialism in African Philosophy." African Studies.

Musschenga, A. 2005. "The debate on impartiality: An introduction." Ethical Theory and Moral Practice 8(1-2): 1-10. doi:10.1007/s10677-005-3290-8.

Parfit, D. 2002. "What Makes Someone's Life to Go Best?" In: Ethical Theory: Classic and Contemporary Readings, edited by L. Pojman, 134-140. London: Wadsworth.

Ramose, M. 1999. African Philosophy through Ubuntu. Harare: Mond Books.

Ramose, M. 2003. "The Ethics of Ubuntu." In: The African Philosophy Reader, edited by P. Coetzee and A. Roux, 324-331. New York: Routledge.

Shutte, A. 2001. Ubuntu: An Ethic for a New South Africa. Pietermaritzburg: Cluster Publications.

Singer, P. 1979. Practical ethics. Cambridge: Cambridge University Press.

Sumner, L. 1992. "Two Theories of the Good." Social Philosophy \& Policy 9(02): 1-14. doi:10.1017/S0265052500001370.

Tshivhase, M. 2013. "Personhood: Social Approval or a Unique Identity?" Quest: An African Journal of Philosophy 25: 119-140.

Tutu, D. 1999. No Future without Forgiveness. New York: Random House.

Van Niekerk, J. 2007. "In Defence of an Autocentric Account of Ubuntu." South African Journal of Philosophy 26(4): 364-368. doi:10.4314/sajpem.v26i4.31494.

Warnock, G. 1971. The Object of Morality. London: Methuen.

Williams, B. 1981. Moral Luck. Cambridge: Cambridge University Press. doi:10.1017/ CBO9781139165860.

Wiredu, K. 1992. "Moral Foundations of an African Culture." In: Person and Community: Ghanaian Philosophical Studies, 1, edited by K. Wiredu and K. Gyekye, 192-206. Washington, DC: The Council for Research in Values and Philosophy.

Wiredu, K. 1996a. Cultural Universals and Particulars: An African Perspective. Indianapolis: Indiana University Press.

Wiredu, K. 1996b. "Reply to English/Hamme." Journal of Social Philosophy 27(2): 234-243. doi:10.1111/j.1467-9833.1996.tb00248.x.

Wiredu, K. 1999. "Society and democracy in Africa." New Political Science 21: 33-44.

Wiredu, K. 2004. "Introduction: African Philosophy in Our Time." In: A Companion to African Philosophy, edited by K. Wiredu, 1-27. Oxford: Blackwell Publishing.

Wiredu, K. 2005. "On the Idea of a Global Ethic." Journal of Global Ethics 1: 45-51.

Wiredu, K. 2008. "Social Philosophy in Postcolonial Africa: Some Preliminaries Concerning Communalism and Communitarianism." South African Journal of Philosophy 27(4): 332-339. doi:10.4314/sajpem.v27i4.31522.

Wiredu, K. 2009. "An Oral Philosophy of Personhood: Comments on Philosophy and Orality." Research in African Literatures 40(1): 8-18. doi:10.2979/RAL.2009.40.1.8.

Wolf, S. 1992. "Morality and Partiality." Philosophical Perspectives 6: 243-59. doi:10.2307/2214247. 